\title{
A posição de Husserl no debate sobre a relação entre a Psicologia e a Lógica O lugar da experiência em Prolegômenos
}

\section{The position of Husserl in the debate on the relations between the Psychology and the Logic \\ The place of experience in Prolegomena}

\author{
Prof. Dr. Carlos Diógenes C. Tourinho \\ cdctourinho@yahoo.com.br \\ Universidade Federal fluminense
}

O presente artigo aborda o lugar reservado à experiência em "Prolegômenos à Lógica Pura" (1900). Apresenta a controvérsia entre psicologistas e adeptos de uma lógica "formal". Os primeiros tomam os processos psicológicos para a fundamentação da lógica, ao passo que os últimos concentram-se unicamente em estruturas meramente formais. $\mathrm{O}$ artigo mostra que Husserl não incorre nem em um empirismo psicologista, nem concorda inteiramente com o modo como os argumentos dos lógicos são apresentados. Husserl se depara com duas tarefas principais: 1) afirmar uma dualidade entre o ideal e o real; 2) pensar a relação entre o ato de pensar e o conteúdo lógico do pensamento. É esta última tarefa que exigirá de Husserl uma posição específica quanto ao lugar reservado à experiência.

\section{PALAVRAS-CHAVE \\ Edmund Husserl; Prolegômenos; \\ Psicologismo; Lógica Formal; Experiência}

The present paper approaches the place reserved to experience in "Prolegomena to Pure Logic" (1900). Present the controversy between psychologists and adherents of the logic "formal". The article shows that Husserl does not incur nor in an empiricism psychologist nor fully agrees with the way how the logical arguments are presented. Husserl is faced with two main tasks: 1) assert a duality between the ideal and the real; 2) thinking the relation between the act of thinking and the logical content of thought. It is this last task that will require a specific position of Husserl as the place reserved to experience.

\section{KEY-WORDS}

Edmund Husserl; Prolegomena;

Psychologism; Logic Formal; Experience 


\section{Introdução}

O presente artigo tem como objetivo destacar a importância do lugar reservado à experiência nas origens da fenomenologia, especificamente, no Quarto Capítulo de "Prolegômenos à Lógica Pura" (Prolegomena zur reinen Logik), primeiro volume das Investigações Lógicas (Logische Untersuchungen) de Husserl, obra de 1900, considerada um marco na história do pensamento fenomenológico. O próprio Husserl nos diz, no prefácio da segunda edição de Investigações Lógicas, escrito em 1913, que: “As Investigações Lógicas foram, para mim, uma obra de ruptura e, por isso, não um fim, mas um começo" (HUSSERL, 1913, p. VIII). Pretende-se mostrar que, perante a conhecida controvérsia do final do século XIX entre os psicologistas e os lógicos anti-psicologistas, assumir uma posição quanto ao papel da experiência (Erfahrung) na discussão sobre a relação entre a lógica e a psicologia era algo de fundamental importância para que se pudesse propor, naquele contexto, uma terceira linha de investigação. Afinal, se os psicologistas tomam, ao reeditarem um empirismo no último quarto do século XIX, a experiência como fonte de conhecimento, tomando os processos psicológicos de consciência como ponto de partida para a fundamentação da lógica - concebendo, inclusive, a lógica como uma "técnica do pensar" - e, com isso, incorrendo no equívoco de confundir o "ideal" com o "real", os argumentos apresentados pelos lógicos anti-psicologistas adeptos de uma lógica "pura" ou "formal" - apesar de não incorrerem nos equívocos psicologistas - não foram, nos termos de Husserl, adequadamente trabalhados, permanecendo os mesmos "obscurecidos por diversas incorreções" (HUSSERL, [1900] 1913, p. 59). Neste sentido, na referida discussão sobre a fundamentação da lógica, os lógicos anti-psicologistas apoiar-seiam unicamente em estruturas meramente formais, em princípios lógicos (tal como o princípio da silogística) cuja validade seria a priori e, portanto, independente da experiência.

Porém, no que se refere à questão da relação entre o ideal e o real, entre o ato de pensar (Denken) e as formas do pensamento (Gedanke), o artigo apontará que, em linguagem kantiana, Husserl assume, ao final do Quarto Capítulo de "Prolegômenos", uma posição específica, reservando um lugar especial à experiência, (tomando-a não como "fonte" de conhecimento, mas como uma condição que se impõe quando pensamos a relação entre o ato de pensar e o conteúdo ideal do pensamento). Afinal, como faz questão de esclarecer o próprio Husserl, "as leis lógicas não são inferências da experiência psicológica, embora só por meio dela se possam conhecer" (HUSSERL, [1900] 1913, pp. 81-82). No que se refere à referida questão, Husserl não incorre, assim, nem em um empirismo nos moldes psicologistas (tal como aquele reeditado por autores 
como: Stuart Mill, Alexander Bain, dentre outros), nem tampouco concorda inteiramente com o modo como os adeptos de uma lógica formal (tais como Herbart, Hamilton, dentre outros) apresentam os seus argumentos contra o psicologismo. Coloca-se aí, para Husserl, a exigência de assumir uma posição em relação ao lugar reservado à experiência. Posição essa que inauguraria uma terceira frente de investigação nas origens da filosofia contemporânea. Passemos, então, a um exame mais detalhado de cada um dos argumentos apresentados em "Prolegômenos" a respeito do tema em questão.

\section{A crítica de Husserl ao psicologismo em "Prolegômenos" (1900)}

Pode-se dizer que nos "Prolegômenos" das Investigações Lógicas (1900), especificamente, no terceiro e no quarto capítulos, o momento crucial repousa sobre as críticas de Husserl ao psicologismo - cujo equívoco maior consistiria na insistência dos psicólogos do último quarto do século XIX em buscar uma fundamentação para as leis da lógica nos processos psíquicos, em tomar as leis do pensamento em termos de leis psicofísicas, propondo uma espécie de "física do pensamento". Lipps afirma-nos, a esse respeito, que: "A Lógica é física do pensar ou ela não é nada” (apud HUSSERL, [1900] 1913, p. 55). Tal insistência psicologista culminaria, segundo Husserl, em um ceticismo e em um relativismo nocivos à pretensão da referida fundamentação e que deveria, portanto, ser evitado a todo custo. Entre os psicologistas do final do século XIX citados por Husserl, tais como Lipps, Wundt, Stuart Mill, dentre outros, prevalece a convicção segundo a qual os fundamentos da lógica encontram-se na própria psicologia, de maneira que a lógica - concebida não como uma disciplina meramente formal e demonstrativa, mas sim como uma "técnica do pensar" (l'art de penser) - consistiria apenas em uma parte ou ramo da ciência psicológica. Nos termos de Lipps: "A lógica é uma disciplina psicológica, tão certo quanto o conhecer só ocorre na psique, e o pensar, que nele se completa, é um acontecer psíquico" (HUSSERL, [1900] 1913, p. 52). Em tal concepção psicologista, caberia à psicologia fornecer o fundamento teórico para a construção de uma técnica lógica e, de acordo com tal concepção, jamais se poderia afastar da lógica o seu conteúdo psicológico. Para os adeptos do psicologismo, tal conteúdo psicológico indissociável já estaria presente nos conceitos constitutivos das leis lógicas, tais como os conceitos de "verdade" e "falsidade", "afirmação" e "negação", "universalidade" e "particularidade", "premissa" e "consequência", e assim por diante. 
Enquanto "ciência de fatos" e, portanto, enquanto ciência cujo objeto se refere a questões de fato (matters offact), a psicologia - ao modo de consideração das ciências positivas - adota a indução como método de investigação. Procede habitualmente por observação sistematizada de fatos particulares procurando descrever a regularidade do que é observado para inferir, então, o que os cientistas positivistas denominam de "leis gerais". Husserl ([1900] 1913) esforça-se em mostrar que, enquanto regras meramente empíricas (isto é, "aproximativas"), inferidas através da indução exercida pela ciência psicológica, tais "leis gerais" carecem de exatidão absoluta, pois a validade dessas leis depende de "circunstâncias" e, deste modo, não são "leis" no sentido autêntico da palavra, embora muito valiosas, não são mais do que "generalizações vagas da experiência” (vage Verallgemeinerungen der Erfahrung). Para Husserl ([1900] 1913), todas as leis alcançadas por indução consistem, na medida em que carecem de validade absoluta, em leis de probabilidade. Neste sentido, essas mesmas leis psicológicas - tais como, por exemplo, as leis de associação de ideias - não poderiam ser confundidas com as leis da lógica (os princípios lógicos, tais como, as leis da silogística, o princípio da não-contradição, etc.), cuja validade é $a$ priori, cuja fundamentação e justificação se dão não por meio da indução, por meio de suposições probabilísticas, mas por evidências apodíticas apreendidas por intelecção. Daí o próprio Husserl dizer, no $\S 21$, que: "a probabilidade não pode se impor contra a verdade, ou a conjectura contra a intelecção" (HUSSERL, [1900] 1913, p. 64). O erro dos psicologistas em tomar as puras leis do pensamento em termos de leis causais da natureza, confinando-as à esfera do probabilismo, resultaria, segundo Husserl ([1900] 1913), das confusões produzidas pelo próprio modo de consideração naturalista acerca do problema em questão, mais precisamente, por não considerar a distinção crucial entre as leis lógicas (entendidas como "conteúdos do juízo") e os próprios juízos, no sentido de "atos de julgar", acontecimentos reais dotados de causas e efeitos. Confunde-se, portanto, em tal modo de consideração, a lei do pensar com o ato de julgar (em outros termos, o "ideal" com o "real"). Tal confusão leva-nos a conceber a lei como reguladora do processo do pensamento, acrescentando-se, com isso, uma segunda confusão produzida pelo naturalismo entre a "lei lógica" que se refere ao conteúdo do conhecimento e a "lei psicológica" que, em conformidade com a anterior, regularia o processo cognoscitivo. Husserl ([1900] 1913) esforça-se em alertar para os perigos desta segunda confusão, afirmando-nos, no famoso "exemplo da máquina de calcular" (ao final do $\S 22$ de "Prolegômenos"), que há de se considerar a heterogeneidade entre as "leis gerais da aritmética" e as "leis mecânicas" que explicam o funcionamento da 
máquina. Ninguém apelaria, ao tentar explicar tal funcionamento, para as leis da aritmética em detrimento das leis mecânicas determinantes do funcionamento da máquina. O erro maior dos psicologistas do último quarto do século XIX consistiria, portanto, em ignorar as diferenças fundamentais e essenciais entre "lei ideal" e "lei real", entre "regulação normativa" e "regulação causal", entre "necessidade lógica" e "necessidade real", entre "fundamento lógico" e "fundamento real". As leis causais segundo as quais o pensamento se desenvolve de modo a poder justificar-se pelas normas ideais da lógica, e estas mesmas normas seriam, portanto, segundo Husserl ([1900] 1913), coisas inteiramente distintas.

Husserl ([1900] 1913) deixa-nos claro que, ao identificar as leis do conteúdo do ato com as leis que regulam o processo psicológico, os psicologistas acabam por fazer com que a verdade que constitui o conteúdo do ato dependa diretamente do processo psíquico, isto é, da constituição da natureza humana, o que inevitavelmente levar-nos-ia a afirmar que tal verdade não existiria se não existisse essa constituição, conduzindo-nos, assim, a consequências relativistas e céticas. Mais uma vez, Husserl chama-nos a atenção para o que considera fundamental: não podemos confundir o juízo como "conteúdo de juízo" (isto é, como unidade ideal) com o ato de julgar, concreto e real. A psicologia refere-se aos juízos como "assentimentos" (ou "atos de consciência"), ao passo que a lógica considera o juízo como "unidade ideal de significação" (FRAGATA, 1962).

Após abandonar a posição assumida em 1891, em Filosofia da Aritmética (Philosophie der Arithmetik), por meio da qual insistia em buscar os fundamentos da matemática e da lógica em intuições psicológicas, Husserl não hesitaria em reconhecer, a partir de "Prolegômenos" (1900), o mérito dos adeptos de uma lógica "pura", justamente por conta dos mesmos não incorrerem nos equívocos do psicologismo ${ }^{1}$. Neste sentido, conforme afirma Natorp (apud SANTOS, 2010), o texto de "Prolegômenos" teria como fim conduzir o leitor à aceitação de uma lógica "pura" ou "formal" (cuja validade dos princípios seria a priori e, portanto, independente da experiência), único caminho que permitiria escapar

1 Soma-se a esta crítica ao psicologismo a rejeição por parte de Husserl de uma psicologia empírica que ele próprio abraçara (ainda como herança do empirismo de Brentano), em sua Filosofia da Aritmética (Philosophie der Arithmetik), publicada em 1891, com o intuito de contestar a ambição de reduzir os fundamentos da matemática à lógica formal, motivo de um debate importante com Frege na última década do séc. XIX. A rejeição de tal psicologia empírica - na qual Husserl se apoiara ao analisar os conceitos mais básicos da aritmética, incorrendo nos mesmos equívocos psicologistas que denunciaria anos depois - é anunciada explicitamente pelo próprio autor no prefácio da primeira edição dos "Prolegômenos", ao afirmar que: "Nada condenamos mais severamente do que os erros que acabamos de abandonar". Cf. Tourinho, C. D. C "O problema dos fundamentos na fenomenologia de Husserl: o surgimento de um novo idealismo transcendental no séc. XX”. In: Síntese - Revista de Filosofia. Volume 40, n⿳ 126 , janeiro-abril de 2013, pp. 79-80. 
às consequências relativistas e céticas do psicologismo. Apesar de reconhecer o mérito dos lógicos antipsicologistas em não confundir o ideal com o real (o ato de julgar com o conteúdo lógico do juízo), Husserl não hesitará em afirmar, ao final do Capítulo Terceiro de "Prolegômenos", que os pensamentos decisivos apresentados contra o psicologismo pelos adeptos da lógica "formal" não foram adequadamente trabalhados. Tal posicionamento faz com que Husserl conduza o leitor para uma terceira via de investigação. É o que examinaremos a partir de agora.

\section{Os adeptos da lógica "formal", a objeção psicologista e a posição de Husserl}

Husserl ([1900] 1913) lembra-nos, no § 19, que os partidários do que poderíamos chamar de um "antipsicologismo logicista", adeptos de uma lógica formal e demonstrativa (tais como, Jäsche, Herbart, Hamilton, dentre outros) não deixam de fundamentar uma separação rigorosa entre os domínios da lógica e da psicologia. Neste sentido, contestam toda tentativa de fundamentação da lógica na psicologia - e, por conseguinte, a concepção da lógica como disciplina prática, como "tecnologia do pensamento" (Kunstlehre des Denkens) -, afirmando-nos que a psicologia considera o pensar como ele é (enquanto ato psíquico), ao passo que a lógica considera o pensar como deve ser. Se a disciplina psicológica - na investigação positiva do processo psicofísico - se ocupa com "leis da natureza", a lógica ocupa-se com leis normativas do pensar. Enquanto "ciência de fatos" (e, portanto, enquanto ciência experimental), a psicologia esclarece-nos, através da investigação dos processos psicofísicos, como o pensar (Denken) acontece, conduzindo-nos, como em toda ciência positiva, a generalizações empíricas que, como tais, não perdem o seu aspecto contingente. $\mathrm{Na}$ lógica, porém, trata-se não de regras contingentes (de caráter "circunstancial" ou "episódico"), mas necessárias - não de como pensamos, mas de como devemos pensar. Em suma, a lógica teria por objeto as operações do pensamento como elas devem ser (wie sie seins sollen), ao passo que a psicologia diria respeito a estados de fato (matters of fact), contingentes e reais (SANTOS, 2010). Os lógicos antipsicologistas lembram-nos ainda que a psicologia investiga as conexões reais entre os processos de consciência (isto é, os seus "antecedentes" e "consequentes" causais), ao passo que à lógica interessa examinar não essas conexões naturais presentes nos processos psicofísicos, mas sim "conexões ideais" entre proposições. Para os adeptos de uma lógica "formal" ou "pura", a 
lógica seria uma disciplina teorética, independente da psicologia e, ao mesmo tempo, uma disciplina formal e demonstrativa.

Porém, o próprio Husserl ([1900] 1913) afirma-nos que os pensamentos decisivos fornecidos pelos adversários do psicologismo não foram adequadamente trabalhados, de modo que se tomam o partido correto - uma vez que não incorrem nos equívocos psicologistas - os lógicos antipsicologistas nem sempre o fazem de maneira adequada, sobretudo, no que se refere ao modo como apresentam os seus argumentos. Mais precisamente, não basta que os adeptos da lógica "formal" digam que a psicologia e a lógica, que têm por termo o pensamento, sejam ciências distintas na medida em que uma considera o pensamento do ponto de vista explicativo e causal, ao passo que a outra o considera sob o aspecto ideal e normativo. Como vimos, a primeira trata do pensar como ele é (enquanto ato psíquico), ao passo que a segunda lida como o pensar como ele deve ser. Tal posicionamento dos lógicos permite o contra-ataque psicologista.

Em geral, contra esta argumentação, os psicologistas apóiam-se na objeção segundo a qual não poderíamos falar em leis lógicas se nunca tivéssemos tido representações ou juízos atualmente vividos e deles abstraído os correspondentes conceitos lógicos fundamentais. Em suma, ao conceberem a lógica como uma "tecnologia do pensamento" (Kunstlehre des Denkens), os psicologistas perguntam-nos: como os lógicos poderiam buscar as conexões ideais sem levar em consideração as conexões naturais presentes nos processos psicofísicos? Como prescindir das conexões causais entre fatos em troca de conexões ideais, se tais conexões ideais só têm existência enquanto produzidas numa atividade psicológica e real? Afinal, objetam os psicologistas, ainda que se considere tal distinção entre o real e o ideal (entre o ato de pensar e o conteúdo lógico do pensamento), todo raciocínio lógico é indissociável do ato psicológico de pensar. "Chegamos assim ao ponto crucial da questão: como se relaciona a idealidade do pensamento com sua produção psicológica real?" (SANTOS, 2010, p. 110).

Husserl responde, no $\S 23$, a essa objeção psicologista, afirmando-nos que: não se nega que as leis lógicas se manifestem através de atos psicológicos, mas "os pressupostos psicológicos ou componentes da afirmação duma lei não se podem confundir com os elementos lógicos do seu conteúdo" (HUSSERL, [1900] 1913, p. 71). Tal redução psicologista das leis lógicas às leis psicológicas teria, conforme foi dito, levado Lipps a considerar a lógica uma "física do pensamento" (apud HUSSERL, [1900] 1913, p. 55). Considerada como uma disciplina da psicologia, a lógica seria, na concepção de Lipps, uma "ciência indutiva". Todo esforço de Husserl consiste em mostrar, ao denunciar os equí- 
vocos cometidos pelos psicologistas, que dos fatos não podemos haurir leis de caráter absoluto, de modo que, se o saber humano estivesse, em última instância, fundado na psicologia, todo ele ficaria inconsistente (teríamos assim profundamente abalado o valor de todo o conhecimento) e, por conseguinte, estaria aberto o caminho para um ceticismo radical que "é, por definição, evidentemente contraditório" (HUSSERL, [1900] 1913, p. 112). Portanto, para Husserl, não poderemos confundir o modo concreto como se manifestam as leis lógicas com as mesmas leis em si.

Husserl recupera, então, ao final do Capítulo Quarto de "Prolegômenos", no $\S 24$ Continuação (Fortsetzung), a lição - anunciada por Kant na Introdução da Crítica da Razão Pura - segundo a qual "Todo o conhecimento 'começa com a experiência', mas não 'deriva', só por isso, da experiência” (HUSSERL, [1900] 1913 , pp. 81/82) ${ }^{2}$. Em outros termos, as leis lógicas não são inferências da experiência psicológica, embora só por meio dela se possam conhecer. Assim, em particular, embora não sejam "leis indutivas", as leis lógicas são conformes à experiência. Especificamente, somente neste sentido, como nos diz Husserl ([1900] 1913) no $\S 20$, ao final do Capítulo Terceiro, a psicologia participa na fundamentação da lógica, mas não que participe sozinha, não que estabeleça o fundamento essencial da lógica. Eis um ponto decisivo em uma das questões referentes à delimitação da lógica - anunciada por Husserl ao final da Introdução de "Prolegômenos" - a saber, "se a lógica é uma disciplina meramente formal ou em que medida diz respeito também à sua 'matéria"” (HUSSERL, [1900] 1913, p. 7).

Tal insistência psicologista em não reconhecer tais distinções entre o conteúdo lógico do ato de julgar e o ato propriamente dito, entre as leis lógicas e as leis psicológicas, culminaria, segundo Husserl ([1900] 1913), em um ceticismo e em um relativismo nocivos e que deveria, portanto, ser evitado a todo custo. Por outro lado, apesar de reconhecer o mérito dos lógicos antipsicologistas de não incorrer nos equívocos psicologistas, de não confundir o ideal e o real (o ato de julgar com o conteúdo lógico do juízo), a ponto de dizer que o lado mais importante da verdade pareceria estar do lado antipsicologista, Husserl não deixa de ressaltar, ao final do Capítulo Terceiro, no § 20, que, da parte dos lógicos antipsicologistas, os pensamentos decisivos apresentados contra o psicologismo não foram adequadamente trabalhados, permanecendo os mesmos "obscurecidos por diversas incorreções” (HUSSERL, [1900] 1913, p. 59). Se os psicologistas

2 Já na edição B da Crítica da Razão Pura (Kritik der reinen Vernunft), Kant afirmara-nos: "Se, porém, todo o conhecimento se inicia com a experiência, isso não prova que todo ele derive da experiência" (Wenn aber gleich alle unsere Erkenntniss $m$ i t der Erfahrung anhebt, so entspringt sie darum doch nicht eben alle aus der Erfahrung). Cf. Kant, I. Kritik der reinen Vernunft, Einleitung, p. 47 
se equivocam, na discussão sobre a relação entre a lógica e a psicologia, pela insistência em fundamentar a lógica em fatos de consciência, confundindo as leis do pensamento com as leis causais da natureza, os lógicos antipsicologistas confinam-nos, na referida discussão, apesar de não incorrerem nos equívocos psicologistas, à esfera de estruturas meramente formais, de princípios - tal como o princípio da silogística - cuja validade seria a priori e, portanto, independente da experiência. Com isso, sobretudo, ao distinguirem os domínios da psicologia e da lógica, afirmando-nos que a primeira investiga o pensar como ele é, ao passo que a segunda trata do pensar como deve ser, os adeptos da lógica "formal" acabam por deixar desapercebida a questão referente ao estatuto da relação entre o conteúdo lógico do pensamento e o ato psicológico de pensar. E será justamente este ponto que merecerá da parte de Husserl uma atenção especial.

\section{Considerações finais: a "dupla tarefa" de Husserl em "Prolegômenos"}

Conforme vimos, já em 1900, em "Prolegômenos", primeiro volume das Investigações Lógicas, perante a controvérsia entre os psicologistas - adeptos da concepção segundo a qual a lógica seria uma "tecnologia do pensar" (Kunstlehre des Denkens) cujos fundamentos encontrar-se-iam em processos psicológicos - e os lógicos antipsicologistas (adeptos de uma lógica "pura", independente da psicologia e, simultaneamente, formal e demonstrativa), Husserl se vê diante de uma dupla tarefa. Por um lado, para impedir a disseminação dos equívocos psicologistas, nos quais se pode atestar uma "confusão de domínios" (Gebietsvermengung), uma mistura do que é heterogêneo - uma confusão de fronteiras cujas consequências nos conduziria, inevitavelmente, a um ceticismo irremediável - era necessário apresentar argumentos contundentes que reiterassem o discernimento entre o real e o ideal (entre "leis naturais" e "leis do pensamento"), afastando, de uma vez por todas, tais equívocos resultantes do projeto psicologista de fundamentação da lógica na psicologia; por outro lado, tal discernimento de domínios não isentaria Husserl de pensar o estatuto da relação entre o conteúdo lógico do pensamento e o próprio ato psicológico de pensar. Afinal, respondendo ao contra-ataque psicologista segundo o qual todo raciocínio lógico é indissociável do ato psicológico de pensar, Husserl afirma-nos que é inegável que o primeiro somente se dê por intermédio do segundo. Em seus termos: "Ninguém duvidará de que o conhecimento das leis lógicas como ato psíquico, pressupõe a experiência particular de que esse conhecimen- 
to tem os seus fundamentos na intuição concreta" (HUSSERL, [1900] 1913, p. 75). A constatação de tal relação não nos impele, contudo, a confundir os "pressupostos" psicológicos com os pressupostos, razões ou premissas lógicas que determinam o modo como devemos pensar de acordo com as leis da lógica.

Husserl não poderia, deste modo, responder à questão do estatuto da relação entre o ato psicológico de pensar e o conteúdo lógico do pensamento sem que ele mesmo assumisse, especificamente, no Quarto Capítulo de "Prolegômenos", uma posição específica quanto ao lugar reservado à experiência (Erfahrung). Afinal, se os psicologistas tomam, ao reeditarem um empirismo no último quarto do século XIX, a experiência como "fonte do conhecimento", adotando a indução como método de investigação (tomando os fatos naturais da consciência como ponto de partida para a fundamentação da lógica, incorrendo, com isso, no equívoco de confundir o ato de pensar com o seu conteúdo ideal), os argumentos apresentados pelos lógicos antipsicologistas (adeptos de uma lógica "formal" ou "pura") - apesar de não incorrerem nos equívocos psicologistas - confinar-nos-iam à esfera de estruturas meramente formais, de modo que, para eles, a lógica seria uma disciplina meramente formal e demonstrativa, cuja validade dos princípios independeria da experiência. Com isso, os lógicos evitariam a questão do estatuto da relação entre o conteúdo lógico do pensamento e o ato de pensar propriamente dito. Soma-se a isso a insuficiência constatada por Husserl do modo como os pensamentos decisivos contra o psicologismo são apresentados pelos adeptos da lógica formal. Conforme vimos, ao afirmarem, com o intuito de distinguir as fronteiras da psicologia e da lógica, que a psicologia investiga o pensamento como ele é (enquanto ato psicológico), ao passo que a lógica trataria de como as operações do pensamento devem ser, os adversários do psicologismo se expõem ao contra-ataque psicologista, cuja ênfase recai sobre a questão do estatuto da relação entre o ato psicológico de pensar e o conteúdo ideal do pensamento. Essa segunda questão - diga-se de passagem, crucial - é justamente a questão que irá impor a exigência de assumir uma posição em relação ao lugar reservado à experiência. Husserl saberá reconhecer a importância desta exigência: afinal, como não ignorar a questão da relação entre o ideal e o real (tarefa que, por si só, conforme dissemos, leva-nos a assumir uma posição quanto ao papel da experiência), sem cair em um empirismo nos moldes psicologistas?

Conforme se mostrou, em linguagem kantiana, Husserl assume, ao final do Quarto Capítulo, uma posição específica quanto à experiência, tomando-a não como "fonte de conhecimento", mas como começo imprescindível para se pensar a referida relação entre os processos psicológicos e o conteúdo lógico do pensamento, sem incorrer, contudo, em um empirismo nos moldes psicologistas. Tal posicionamento seria, nas origens da filosofia contemporânea, de fun- 
damental importância para que pudesse surgir, no quadro da controvérsia entre psicologistas e adeptos da lógica formal, uma terceira linha de investigação no começo do séc. XX, a partir da qual começaria a se traçar, mais a frente, o projeto da filosofia fenomenológica. Diante da controvérsia entre psicologistas e lógicos e, sobretudo, diante da dupla exigência que o referido debate impõe (esclarecer a distinção entre as fronteiras do real e do ideal, bem como pensar a relação entre ambos), a aposta de Husserl consistirá, conforme será possível notar, no pouco mais de dez anos que se seguirão à primeira edição das Investigações Lógicas, particularmente, em Ideias para uma fenomenologia pura e filosofia fenomenológica (Ideias I), em 1913, na formulação da ideia de um "vivido" (Erlebniss) originário - que é, por definição, intencional, mas que não pode prescindir de um substrato sensível sobre o qual irão atuar, no próprio vivido, os atos intencionais da consciência (TOURINHO, 2012).

Tratar-se-ia, portanto, com a intencionalidade, de uma propriedade essencial da consciência transcendental cuja presença animaria o vivido de significações, tornando-o, com isso, designativo de um objeto. No § 36 de Ideias I, Husserl (1913) afirma-nos que é da essência de todo cogito atual "ser consciência de algo", de tal modo que todos os vividos que possuem tal propriedade são chamados de "vividos intencionais" (ou "atos intencionais", se optarmos por um termo adotado à época das Investigações Lógicas), uma vez que tais vividos são "consciência de algo". Pode-se dizer que são "intencionalmente referidos" a esse algo. Porém, para Husserl, nem todas as vivências (ou atos) são intencionais. Trata-se de uma constatação para a qual Husserl já nos chamava a atenção desde as Investigações Lógicas (1900/1901), afirmando-nos, no $§ 10$ da V Investigação, que existem "atos não-intencionais". Husserl cita-nos como exemplo de atos não-intencionais as próprias sensações, afirmando-nos, no referido parágrafo: "Que nem todas as experiências sejam intencionais é provado pela [existência de] sensações e complexos sensacionais" (HUSSERL, [1900/1901], p. 369). No § 11 da mesma V Investigação, procurando exemplificar atos do tipo "não-intencional", faz ainda a seguinte colocação: "Não vejo impressões de cores, mas coisas coloridas; não ouço impressões de sons, mas a canção cantada, etc" (HUSSERL, [1900/1901], p. 374). Portanto, para Husserl (1913), novamente, nos termos do $\S$ 36 Ideias I, a consideração do fluxo de vividos em geral engloba tanto os vividos desse fluxo que possuem a propriedade de "ser consciência de algo", quanto os seus "momentos reais" que, por serem apenas dados, nada designam ainda e, portanto, encontram-se desprovidos de tal propriedade intencional, tais como os dados de sensação, os dados de cor, de tato, de som e assim por diante.

No parágrafo $\S 85$ de Ideias I, Husserl (1913) retoma o tema em questão, destacando-nos que, no fluxo de vividos, além da "camada intencional" - que 
"anima" a vivência de significações, tornando-a designativa de um objeto todo vivido possui um "substrato" sensível e, como vimos, "não-intencional". Segundo Husserl, tal substrato - na medida em que é suporte para uma intencionalidade - se torna uma peça importante para o entendimento da trama que envolve a formação intencional (ou as doações de sentido de diferentes níveis) no vivido como um todo. A "camada intencional" age sobre os momentos sensíveis, "animando-os", dando-lhes sentido (sinngebende). Trata-se, segundo Husserl, de uma camada por meio da qual o próprio vivido intencional se realiza, "[...] a partir do elemento sensual que em si nada tem de intencional" (HUSSERL, 1913, p. 172). Apesar dessa dualidade que coloca, de um lado, os momentos sensíveis (não-intencionais) e, de outro, a camada intencional, Husserl não deixa de enfatizar o laço que os une, uma vez que, no vivido como um todo, os dados sensíveis seriam como a "matéria" (que nada tem de intencional, mas que serve de "substrato" para a formação intencional), ao passo que a camada intencional seria como a "forma" (cujo papel no vivido seria propriamente o de promover a doação de sentido).

Ainda que esta doação de sentido não derive da matéria, não começa sem ela, pois é sobre a matéria que a camada intencional agirá, atribuindo-lhe significação. Aqui, Husserl expressa novamente a lição kantiana, já anunciada ao final do Capítulo Quarto de "Prolegômenos": o conhecimento não deriva da experiência, mas deve começar com ela. Trata-se, certamente, da influência exercida pelo neokantismo da Escola de Marburg - principalmente, através de Natorp - sobre o pensamento de Husserl, nas origens da fenomenologia (PAISANA, 1997). Os influxos exercidos pelo neokantismo sobre o projeto da fenomenologia transcendental de Husserl seriam, certamente, de suma importância ${ }^{3}$

Porém, este mesmo projeto não seria possível sem que houvesse, por parte de Husserl, uma redefinição de alguns conceitos centrais do idealismo kantiano, tais como, os conceitos de "transcendental", "apercepção", "fenômeno", etc. Eis um ponto decisivo a ser considerado, até mesmo para que possamos entender Husserl além de Kant. Um exame mais detalhado desta questão ficará, porém, para uma outra ocasião.

3 No que se refere às influências que a leitura de Kant exerceu sobre o pensamento husserliano, sobretudo, a partir de 1907, Walter Biemel - editor alemão das "Cinco Lições" (Die Idee der Phänomenologie - Fünf Vorlesungen) - lembra-nos que: "Husserl, nesta época, ocupou-se detidamente de Kant; desta ocupação veiolhe a ideia da fenomenologia como filosofia transcendental, como idealismo transcendental [...]". O manuscrito (Setembro de 1907, B II 1) é citado por Walter Biemel no texto de apresentação à edição alemã das "Cinco Lições". Lovaine, Setembro de 1947, p. IX. Em outra ocasião, tivemos a oportunidade de tratar de alguns tópicos referentes à relação entre o idealismo transcendental de Kant e a fenomenologia de Husserl (Cf. Tourinho, C. D. C. "A ampliação da auto-reflexão da consciência: Kant e sua influência sobre a fenomenologia transcendental de Edmund Husserl”. In: In: Princípios - Revista de Filosofia (UFRN). Volume 18, número 30, jul-dez de 2011, pp. 199-210. 
BELL, D. Husserl. The Arguments of the Philosophers. Edited by Ted Honderich. Routledge. London and New York, 1995.

FRAGATA, J. S.I. Problemas da Fenomenologia de Husserl. Braga: Livraria Cruz, 1962.

HUSSERL, E. Logische Untersuchungen. Erster Band. Prolegomena zur reinen Logik. Halle a. d. S.: Max Niemeyer, ([1900] 1913).

.([1901]1913)Logische Untersuchungen. Zweiter Band. Erster Teil. Untersuchungen zur Phänomenologie und Theorie der Erkenntnis. Halle a. d. S.: Max Niemeyer. . ([1907] 1950) Die Idee der Phänomenologie - Fünf Vorlesungen. Husserliana (Band II). Netherlands: Martinuos Nijhoff.

. (1913) Ideen zu einer reinen Phänomenologie und phänomenologischen Philosophie. Erstes Buch: Allgemeine Einführung in die reine Phänomenologie. Halle a. d.S.: Verlag von Max Niemeyer.

KANT, I. Kritik der reinen Vernunft. Leipzig: Verlag von Felix Meiner, ([1787] 1919).

PAISANA, J. Husserl e a Ideia de Europa. Porto: Contraponto, 1997.

TOURINHO, C. D. C. "A ampliação da auto-reflexão da consciência: Kant e sua influência sobre a fenomenologia transcendental de Edmund Husserl'. In: Princípios Revista de Filosofia (UFRN). Volume 18, número 30, juldez de 2011, pp. 199-210.

."O vivido e suas polaridades: oscilações do objeto intencional na fenomenologia de Husserl'. In: Tourinho, C. D. C. (org.) Temas em Fenomenologia. Rio de Janeiro: Booklink Publicações, 2012.
"O problema dos fundamentos na fenomenologia de Husserl: o surgimento de um novo idealismo transcendental no séc. XX'. In: Síntese - Revista de Filosofia.Volume 40, n 126, janeiro-abril de 2013, pp. 73-84.

SANTOS, J. H. Do empirismo à fenomenologia. A crítica do psicologismo nas Investigações Lógicas de Husserl. São Paulo: Edições Loyola, 2010. 